\title{
MAIORIDADE PENAL: A URGÊNCIA DE UMA DISCUSSÃO
}

\author{
Criminal Majority: The Urgency of a Discussion
}

Mayoridade Penal: La Urgencia de una Discusión

Artigo Original

\author{
Majorité Pénale: Urgence de Débat
}

\section{Resumo}

Pesquisas recentes de opinião pública apontam que há um clamor social pela redução da maioridade penal, o que não é diferente no Senado onde tramitam diversas Propostas de Emenda a Constituição (PECs) sugerindo a adoção desta medida como solução para a criminalidade e violência. Diante da urgência de discussão sobre esta temática, o artigo parte do contexto histórico da categoria "menor" e da concepção de adolescente autor de ato infracional constituída pelo Estatuto da Criança e do Adolescente - ECA, com o objetivo de discutir o advento atual da proposta de redução da maioridade penal. Ressalta-se a elaboração das PECs, a atuação da mídia e a opinião pública frente à desconsideração da inimputabilidade de adolescentes. Além disso, é discutido o posicionamento contrário de alguns setores que atuam no âmbito dos direitos humanos, tais como: o Fundo das Nações Unidas para a Infância (UNICEF), o Conselho Nacional dos Direitos da Criança e do Adolescente (CONANDA) e a Secretaria Nacional de Direitos Humanos (SNDH). A base para refutar a proposta de redução da idade penal, apresentada por esses setores, encontra-se na precária ou até mesmo inexistente garantia dos direitos previstos no ECA. Desse modo, torna-se fundamental a defesa pela efetivação da proteção integral à criança e ao adolescente, como forma de prevenir os atos infracionais. Por fim, compreende-se que propostas como a redução da idade penal além de desresponsabilizar o Estado em sua função de assegurar os direitos fundamentais, autoriza a punição e exclusão cada vez mais dos adolescente.

Palavra-chave: maioridade penal; adolescente; ato infracional; opinião pública; psicologia.

\section{Abstract}

Recent public opinion polls show that there is a social outcry by the reducing the legal age, which is not different in the Senate where several Proposed Amendment to the Constitution (PECs) proceed suggesting the adoption of this measure as a solution to crime and violence. Given the urgency of discussion on this subject, the article begin from the historical context of the "minor" category and teenage author conception of an offense constituted by the Child and Adolescent Statute - ECA, in order to discuss the current advent of the reduction of legal age proposal. It emphasizes the development of PECs, media activities and public opinion front to disregard of the unaccountability of teenagers. Moreover, it is argued the contrary position of certain sectors involved in the area of human rights, such as the United Nations Children's Emergency Fund (UNICEF), the National Council for the Rights of Children and Adolescents (CONANDA) and the Human Rights National Secretary (SNDH). The basis for refuting the reduction of the legal age proposal, presented by these sectors, is found on the poor or even non-existent guarantee of the rights foreseen in the ECA. Thus, it is essential the defense for the effecting of the full protection of children and adolescents, in order to prevent illegal acts. Finally, it is understood that proposals such as reducing the penal age plus

\section{Mariana Fonseca Cavalcanti ${ }^{(1)}$ Isabel Fernandes de Oliveira ${ }^{(2)}$}

1) Psicóloga, Mestranda em Políticas Públicas, Movimentos Sociais e Prática do Psicólogo no departamento de Psicologia da Universidade Federal do Rio Grande do Norte (UFRN).

2) Doutora em Psicologia pela Universidade de São Paulo. Professor Adjunto da Universidade Federal do Rio Grande do Norte e do Programa de PósGraduação em Psicologia da UFRN.
Recebido em: 03/03/2015

Revisado em: 19/06/2015

Aceito em: 29/06/2015 
hold harmless the State in its role of ensuring fundamental rights, authorizes the punishment and exclusion increasingly adolescents.

Keywords: criminal majority; teen; misdemeanors; public opinion; psychology.

\section{Resumen}

Recientes investigaciones de opinión pública apuntan que hay un clamor social por la reducción de la mayoridad penal, lo que no es diferente en el Senado donde se tramita diversas Propuestas de Enmienda a la Constitución (PECs), sugiriendo la adopción de esta medida como solución para la criminalidad y la violencia. Ante la urgencia de discusión acerca de este tema, el artículo toma por base el contexto histórico de la categoría "menor" y del concepto de adolescente autor de delito constituida por el Estatuto del Niño y del Adolescente - ENA, con el objetivo de discutir la llegada de la propuesta de reducción de la mayoridad penal. Se sobresale a la elaboración de las PECs la actuación de los medios de comunicación y la opinión pública ante a la desconsideración de la inimputabilidad de los adolescentes. Además, es discutido el posicionamiento contrario de algunos sectores que actúan en el ámbito de los derechos humanos, tales como: Naciones Unidas para la Infancia (UNICEF), el Consejo Nacional de los Derechos Humanos (CONANDA) y la Secretaria Nacional de Derechos Humanos (SNDH). La base para contestar la propuesta de mayoridad penal, presentada por estos sectores, está en la precaria o inexistente garantía de los derechos establecidos en el ECA. Así, es fundamental la defensa por la implementación de la protección integral al niño y al adolescente, como forma de prevención de delitos. Por fin, se comprende que propuestas como la reducción de la edad penal, además de quitar la responsabilidad al Estado en su función de garantizar los derechos fundamentales, autoriza casa vez más la punición y exclusión de los adolescentes..

Palavras clave: mayoridad penal; adolescente; delito; opinión pública; psicología.

\section{Résumé}

Des recherches récentes de l'opinion publique montrent un cri de la société pour la réduction de la majorité pénale, ce qui n'est pas diférent au Sénat où circulent des diverses Propositions d'Amendement [emenda] à la Contitution (PECs) qui suggèrent accépter cette décision comme résolution de la criminalité et de la violence. Devant l'urgence de débatre ce thème-là, cet article part du contexte historique de la catégorie " mineur" et de la conception de l'adolescent auteur de l'acte d'infraction conceptualisée par l'Estatut de l'Enfant [criança] et l'Adolescent - ECA, ayant comme but le débattre de la proposition de réduction de la majorité pénale. On met en relief l'élaboration des PECs, le rôle des médias, et l'opinion publique en face au discrédit de la non punition des adolescents. On discute encore le positionnement contraire de quelques organizations dans le domaine des Droits
Humains, comme : le Fonds Des Nations Unies Pour L'enfance (UNICEF), le Conseil National des Droits des Enfants et des Adolescents (CONANDA) et le Bureau [Secretaria] National des Droits Humains (SNDH). La base des arguments présentés par ces Organisations pour réfuter la proposition de réduction de la majorité pénale est la précarité, ou plutôt l'inexistence, de la garantie des droits prévus par l'ECA dans ces propositions-là. De cette façon, il est de grande importance qu'il y ait la défense de l'éfétivation de la protection totale de l'enfant et de l'adolescent comme un moyen de prévenir les actes d'infractions. Enfin, on conclut que des propositions de réduction de la majorité pénale retire la résponsabilité de l'État de sa fonction d'assurer les droits fonfamenteaux des adolescents autant qu'elles autorizent de plus en plus leurs punition et exclusion.

Mots-clés: majorité pénale; adolescent; acte d'infraction; l'opinion publique; psychologie.

A temática da redução da maioridade penal adquiriu maior urgência em termos de discussão a partir da tramitação no Senado de diversas Propostas de Emendas à Constituição (PECs) que possibilitam a consideração da imputabilidade penal de maiores de 16,14 e até 12 anos de idade. Essa discussão ganhou contornos mais intensos nas últimas eleições, cujos posicionamentos dos candidatos se dividiam entre a concordância e a discordância à redução.

Ao contextualizar historicamente as políticas públicas voltadas à população infantojuvenil, nota-se que os primeiros serviços de assistência e proteção à infância e adolescência, ainda em 1921, dirigiam-se aos "menores" abandonados e delinquentes sob uma ótica reformista (Rizzini, 2008). O tratamento destinado a eles restringia-se à internação em estabelecimentos que visavam à correção e disciplina, uma vez que a concepção jurídica de "menoridade" referia-se a sujeitos que ofereciam risco à sociedade. Percebe-se que o próprio ordenamento jurídico orientava o imaginário coletivo ao entendimento do "menor" como sujeito que possui capacidade de cometer infrações. Dessa forma, a legislação regulamentava a internação de "menores" marginalizados, promovendo uma espécie de "faxina" social.

Quase cem anos depois, mesmo após a aprovação do Estatuto da Criança e do Adolescente - ECA (Lei. 8.069, de 13 de Julho de 1990) e do Sistema Nacional de Atendimento Socioeducativo - SINASE (Lei n 12.594, de 18 de janeiro de 2012), a população ainda não assimilou a proteção integral do adolescente e, como mostram as pesquisas de opinião pública, o apoio ao aprisionamento como solução para violência permanece (Datafolha, 2013). Cabe destacar que as discussões e propostas favoráveis a esse posicionamento emergem principalmente após a ocorrência de crimes que ganham grande repercussão nacional e comoção pública. 
Nesse sentido, a mídia exerce um papel de destaque ao divulgar recorrentemente notícias que envolvem adolescentes autores de atos infracionais. Alguns telejornais, ao veicularem esse tipo de notícia, expõem abertamente críticas ao ECA, ao mesmo tempo em que apontam a redução da maioridade penal como solução para a criminalidade juvenil.

Com base na emergência da discussão sobre a redução da maioridade penal, este artigo pretende, além de contextualizar as primeiras políticas públicas para os adolescentes, bem como o advento das PECs que defendem mudanças na legislação desta população, discutir os argumentos contrários a essa medida, expostos por setores que atuam no âmbito dos direitos da criança e do adolescente, a exemplo do Fundo das Nações Unidas para a Infância (UNICEF), do Conselho Nacional do Direito da Criança (CONANDA), do Conselho Federal de Psicologia (CFP) e da Ordem dos Advogados do Brasil (OAB), para citar alguns.

\section{Do Menor ao Adolescente Infrator: Breve Contexto Histórico}

Durante o Brasil Republicano, houve euforia na valorização política da chamada "infância ideal", com suas demandas materiais, higiênicas, morais e afetivas, representada como princípio da ordem e do progresso. Consequentemente, não se enquadrava aqui a criança que vivia à margem dessa concepção ideal, considerada pelo Estado um elemento desestabilizador da ordem vigente (Márques, 2011).

Nesse cenário, desenvolveu-se a noção jurídica de "menoridade", a qual identificava, de forma técnica, o indivíduo pobre e com idade inferior a dezoito anos. A esse indivíduo só restava a institucionalização disciplinadora na forma de abrigos, asilos e prisões. Desde então, conforme apontam estudos realizados na década de 1980, o termo "menoridade" passou a ser considerado no imaginário popular brasileiro como indicativo de periculosidade (Márques, 2011).

Essa representação do adolescente como "menor" referia-se à criança e ao adolescente pobre que perambulava pelas ruas e cujo destino era a delinquência. Assim, todo o sistema legislativo voltado para a criança e o adolescente estava organizado em torno da punição de "delinquentes", e não no cuidado àquele que transgrediu uma norma (Volpi, 1997).

Em 1927, foi promulgado o primeiro Código de Menores, instrumento legal destinado à regulamentação e disciplinarização desSes sujeitos. $\mathrm{O}$ código se fundamentava na Doutrina de Situação Irregular - isto é, os abandonados, carentes e infratores, e não a totalidade da população infantojuvenil. Sua política estava baseada no caráter punitivo e era representada institucionalmente por um órgão responsável pelo estabelecimento da política de bem-estar do menor: o Serviço de Assistência ao Menor (SAM).

A dinâmica institucional do SAM era inapropriada e os "menores" estavam sujeitos a condições de despreparo dos técnicos, promíscuas e de espancamento. Devido a esse cenário de descaso com o atendimento das crianças e dos adolescentes, "o SAM transformou-se em sinônimo de horror" (Gomide, 2009, p. 16).

$\mathrm{Na}$ tentativa de redimir a imagem desgastada do SAM, em 1964, foi criada pela Junta Militar a Fundação Nacional de Bem-Estar do Menor (FUNABEM). Seu objetivo consistia em estabelecer as diretrizes nacionais para as políticas e programas de atendimento às crianças e aos adolescentes considerados em situação irregular, priorizando a "segurança pela disciplina". Entretanto, as práticas de violência física e psicológica permaneciam da mesma forma que no SAM (Gomide, 2009).

Esse quadro permanece invariado até meados da década de 1980, quando, após mais de vinte anos da ditadura militar, os movimentos sociais se reorganizam no Brasil e a sociedade mobilizou-se em prol da consolidação de um Estado democrático. Dentre as reivindicações de reforma do Estado, destaca-se a busca pelos direitos e proteção das políticas públicas para a criança e o adolescente. Tais demandas convergiram e redundaram, na forma da Lei. 8.069, de 13 de Julho de 1990, o Estatuto da Criança e do Adolescente - ECA (Volpi, 1997).

O ECA considera adolescentes pessoas entre 12 e 18 anos de idade, sujeitos de direitos e em situação peculiar de desenvolvimento. Destaca-se que:

É dever da família, da sociedade e do Estado assegurar à criança e ao adolescente, com absoluta prioridade, o direito à vida, à saúde, à alimentação, à educação, ao lazer, à profissionalização, à cultura, à dignidade, ao respeito, à liberdade, à convivência familiar e comunitária, além de deixá-los a salvo de toda forma de negligência, discriminação, exploração, violência, crueldade e opressão. (Brasil, 1990, p. 23)

Sobre o ato infracional, não caracterizado como crime, o ECA ressalta que somente os adolescentes são passíveis de cometê-lo, face às peculiaridades que o cercam. Dessa forma, cabe aos adolescentes cumprir as chamadas medidas socioeducativas, cujo objetivo é a reinserção social e o fortalecimento dos vínculos familiares e comunitários. Portanto, essas medidas têm função pedagógica, mesmo quando se trata da privação de liberdade (Brasil, 1990).

As medidas socioeducativas são as seguintes: “Advertência, obrigação de reparar o dano, prestação de serviço à comunidade, liberdade assistida, inserção em regime de semiliberdade e internação em estabelecimento 
educacional" (Brasil, 1990, p. 41). Com relação à aplicabilidade dessas medidas, o Estatuto preconiza que as características e a gravidade da infração devem ser consideradas. Além disso, elas devem respeitar as peculiaridades da adolescência, assegurar proteção à vida e proporcionar a superação da exclusão por meio da reinserção social.

Cumprir com os princípios estabelecidos pelo ECA representa um desafio no qual os conceitos legais deveriam ser transpostos para a prática com vistas à sua efetivação. Dessa forma, as instituições socioeducativas teriam que priorizar a execução das novas leis voltadas aos adolescentes, considerando as suas peculiaridades e ao mesmo tempo distinguindo-se do sistema prisional - tanto no que se refere às instalações físicas quanto na própria dinâmica institucional. O fim proposto é o de oportunizar aos adolescentes uma ressignificação dos seus padrões de socialização (Campos \& Francischini, 2005).

Entretanto, segundo o Conselho Federal de Psicologia (2010), o que tem prevalecido em muitas unidades de internação no Brasil são condições de superlotação, insalubridade, estruturas inadequadas, além da ausência de propostas claras de funcionamento operacional. Ademais, acrescenta-se a gravidade de circunstâncias, como tortura física e psicológica, abusos sexuais, maus tratos, isolamento dos adolescentes, incomunicabilidade, humilhação e excesso de medicalização.

Assim, apesar dos avanços na legislação, evidenciase na prática a existência de instituições com o modelo de atendimento semelhante ao que existia no Serviço de Assistência ao Menor (SAM): instalações inadequadas e atuação de profissionais baseadas no modelo repressivo e violador de direitos (Zappe et al., 2011). Desse modo, o que se percebe claramente é que "a Doutrina da Proteção integral não foi assimilada de modo uniforme pelo conjunto da população brasileira" (Zappe et al., 2011, p. 129).

Diante dessa situação, foi aprovada em janeiro de 2012 a Lei 12.594/12, que instituiu o Sistema Nacional de Atendimento Socioeducativo (SINASE), oriundo de uma construção coletiva realizada através de encontros regionais que envolveram diversos setores do governo e representantes de entidades e operadores do Sistema de Garantia de Direitos. O objetivo é regulamentar a execução das medidas socioeducativas (Brasil, 2012).

O caráter pedagógico da medida socioeducativa é reafirmado, priorizando as medidas em meio aberto (prestação de serviço à comunidade e liberdade assistida) em detrimento às medidas restritivas de liberdade (semiliberdade e internação em estabelecimento educacional). Para aplicação dessas últimas, deve-se obedecer ao caráter de excepcionalidade e brevidade, tendo em vista a estratégia de evitar a tendência crescente de internação dos adolescentes, o que dificulta a inclusão social dos egressos do sistema socioeducativo (Brasil, 2012).
O SINASE prioriza também a municipalização dos programas em meio aberto e a regionalização dos programas de privação de liberdade, a fim de garantir o direito à convivência familiar e comunitária dos adolescentes, bem como as especificidades culturais. Para isso, considera-se a intersetorialidade e a corresponsabilidade da família, da comunidade e do Estado no compromisso partilhado para avançar na garantia da absoluta prioridade da criança e do adolescente. Em linhas gerais, com as formulações das diretrizes do SINASE, viabilizam-se as condições possíveis para que o adolescente que comete ato infracional deixe de ser considerado como problema e torne-se prioridade social (Conselho Nacional dos Direitos da Criança e do Adolescente [Conanda], 2006).

Cabe destacar que recentemente o Conselho Nacional do Ministério Público (CNMP) divulgou um relatório fruto de inspeções realizadas por promotores da justiça em todo pais, de março 2012 a março de 2013, em 88,5\% das unidades de internação e semiliberdade. O relatório, cujos dados foram analisados à luz do ECA e do SINASE, aponta que $o$ atendimento socioeducativo nessas unidades está distante do ideal sustentado pela legislação. Ainda persistem, conforme constatado, as semelhanças com presídios, a superlotação, as péssimas condições de higiene e as escassas oportunidades de profissionalização e escolarização (Conselho Nacional do Ministério Público [CNMP], 2013).

\section{A Espetacularização do Adolescente Criminoso e a Proposta de Redução da Maioridade Penal}

Corroborando com a não assimilação da proteção integral pela população, mesmo decorridos 25 anos, o Estatuto da Criança e do Adolescente ainda faz parte do imaginário coletivo como sendo um instrumento de incentivo à delinquência e à impunidade conferidas aos adolescentes (Márques, 2011).

Nesse sentido, a mídia reforça cada vez mais esse imaginário de descrença do ECA, ao mesmo tempo em que espetaculariza ${ }^{1} \mathrm{o}$ ato infracional, defendendo a criminalização dos adolescentes e atribuindo a esses mesmos sujeitos os altos índices de violência. Expõe-se que eles são "protegidos" pela lei e não respondem pelos atos cometidos (Hage \& Araújo, 2013).

Ao culpar os adolescentes pelo aumento da violência, a mídia não se baseia em dados de pesquisas como os que apontam a Secretaria Nacional de Direitos Humanos: entre 2002 e 2011, os casos de homicídios cometidos por adolescentes reduziram de $14,9 \%$ para $8,4 \%$; os casos de

1 Embora não seja objetivo do artigo explorar a teoria do espetáculo, apresentada em A Sociedade do Espetáculo, convém ressaltar que a utilização do termo aqui remete diretamente ao conceito de Guy Debord (1997). 
latrocínios também reduziram de 5,5\% para $1,9 \%$, bem como os de estupro, de 3,3\% para 1\% (Secretaria Nacional de Direitos Humanos [SNDH], 2012).

Segundo Arantes (2013), ao ocorrer um crime brutal que choca a opinião pública e tem a participação de adolescentes, os veículos jornalísticos e midiáticos propagam exaustivamente o fato, recolocando na pauta nacional a discussão sobre redução da maioridade penal. Em seu artigo, a autora menciona cartas de leitores enviadas aos jornais de grande circulação nacional, cujo conteúdo difunde a ideia de que a lei protege os adolescentes e que os direitos humanos servem apenas para defendê-los.

Em abril de 2013, após a ocorrência de um latrocínio cometido por um adolescente na capital paulista, o instituto de pesquisa Datafolha consultou a opinião dos paulistanos a respeito da proposta de redução da maioridade penal. O resultado mostrado foi que, caso houvesse uma consulta popular, 93\% dos paulistanos votariam a favor da redução da maioridade penal de 18 para 16 anos. O Datafolha constatou que o apoio da população em relação a esse tema tem crescido, já que as pesquisas de 2003 e 2006 apontavam, respectivamente, índices de $83 \%$ e $86 \%$ favoráveis à diminuição da maioridade penal (Datafolha, 2013).

Nessa mesma linha, Campos (2009) analisou matérias da revista Veja e do jornal Folha de São Paulo após a ocorrência de dois crimes de grande repercussão pública: o assassinato do casal Liana Friedenbach e Felipe Silva Caffé, envolvendo quatro adultos e um adolescente apelidado de "Champinha" (na época com 16 anos), ocorrido em São Paulo em novembro de 2003; e o assassinato de João Hélio (6 anos), ocorrido no Rio de Janeiro, em 2007, cometido por três adultos e um adolescente de 16 anos. O objetivo do artigo foi analisar a relação desses crimes com a mobilização de tramitação das PECs favoráveis à redução da maioridade penal. $\mathrm{O}$ autor concluiu que a ampla repercussão pública dos dois crimes e a mobilização dos meios de comunicação influenciaram a opinião pública e a Câmara dos Deputados a retomar a proposta de redução à maioridade penal.

Em julho de 2012, o senador Aloysio Nunes (PSDBSP) apresentou uma Proposta de Emenda Constitucional (PEC 33/2012) para alterar a redação dos Arts. 129 e 228 da Constituição Federal. O intuito é acrescentar um parágrafo único prevendo a possibilidade de desconsideração da inimputabilidade de maiores de 16 anos e menores de 18 anos por lei complementar, para crimes hediondos. Essa desconsideração dependerá de um laudo técnico ,o qual comprove a capacidade desses sujeitos em compreender o caráter criminoso de sua conduta (Senado Federal, 2012).

Vale ressaltar que as PECs para redução da maioridade penal são realizadas desde $1993^{2}$. Os argumentos que

2 A PEC 171/1993, de autoria do ex-deputado Benedito Domingues (PP-DF), foi a primeira proposta referente à desconsideração da inimputabilidade de maiores de 16 anos de idade. Em julho de 2015, a Comissão de Cidadania e Justiça (CCJ) aprovou a referida PEC, que segue as embasam são diversos, entre eles, a alegação de que o adolescente tem discernimento para votar e, consequentemente, para compreender o caráter lesivo dos seus atos, o que os obrigam a respondê-los na esfera penal (Campos, 2009).

Desse modo, em 16 de outubro de 2013, o senador e relator Ricardo Ferraço emitiu relatório com parecer favorável à PEC 33/2012 e recusou as demais propostas referentes à redução da maioridade penal, alegando que estas reduziam drasticamente a maioridade penal e que tal redução levaria criminosos adultos a recrutarem adolescentes com idades cada vez mais inferiores. Concomitantemente, a PEC 33/2012 foi considerada uma proposta alternativa, que permite aumentar a responsabilidade do jovem, além de representar uma demanda expressa pela maioria da população (Senado Federal, 2012).

A Comissão de Constituição Justiça e Cidadania (CCJ), em abril de 2014, rejeitou o relatório emitido pelo Senador Ricardo Ferraço, designando novo relator, o Senador Randolfe Rodrigues, e constituindo, assim, um parecer contrário as propostas. Desse modo, a PEC 33/2012 foi considerada inconstitucional, uma vez que a inimputabilidade do adolescente com idade inferior a 18 anos faz parte das garantias individuais e estão entre as cláusulas pétreas da Constituição Federal, só podendo ser modificadas por uma nova Assembleia Nacional. Além disso, também foi ressaltado que a redução da maioridade penal não é solução para combater a violência e que o Estado possui o dever de garantir as condições fundamentais para o desenvolvimento da criança e do adolescente (Senado Federal, 2012). A discussão sobre a PEC 33/2012 terá continuidade no Senado, atualmente, encontra-se em tramitação e será recolocada nas pautas das reuniões da CCJ.

\section{Para Além de Simplesmente Reduzir a Maioridade Penal...}

O assassinato de João Hélio (6 anos), entre outros crimes, recolocou na pauta nacional a discussão sobre o rebaixamento da maioridade penal. No período posterior a esse crime, foram apresentadas três $\mathrm{PECs}^{3}$. Diante desse cenário, o Fundo das Nações Unidas para a Infância (UNICEF) divulgou nota pública sobre a morte dessa criança, solidarizando-se com a família e enfatizando que o projeto de redução da maioridade penal é uma medida intempestiva e inadequada, exigida pela população descrente com a possibilidade de solução frente às verdadeiras causas

em tramitação no Senado.

3 PEC 44/2007 do deputado Rogério Lisboa (DEM-RJ); PEC 73/2007 do deputado Alfredo Kaefer (PSDB-PR); PEC 85/2007 do deputado Onyx Lorenzoni (DEM-RS); e a PEC 87/2007 do deputado Rodrigo de Castro (PSDB-MG). 
da violência, como a desigualdade social, a concentração de renda, o racismo e a insuficiência das políticas públicas. Além disso, ressaltou que medidas estritamente punitivas não resolvem as dores e angústias da sociedade em relação à violência, e que a UNICEF apoia soluções concretas que garantem os direitos dos indivíduos (Fundo das Nações Unidas para a Infância [UNICEF], 2007).

Em 2013, por meio de uma nota pública, o Conselho Nacional dos Direitos da Criança e do Adolescente (CONANDA) também manifestou repúdio às iniciativas de redução da maioridade penal. Entre as considerações apresentadas, estão as que ressaltam as diretrizes do ECA e do SINASE, reafirmando a proteção integral e prioridade absoluta de crianças e adolescentes. Ressaltase a vulnerabilidade e o agravo da violência caso a redução da maioridade penal fosse aprovada, tendo em vista a convivência de adolescentes com adultos no sistema prisional. O CONANDA reconhece, ainda, que os adolescentes que cometem ato infracional, na sua maioria, não tiveram seus direitos fundamentais garantidos, e reduzir a maioridade penal contravém a Constituição Federal e as normativas internacionais. Dessa forma, o CONANDA reafirma a necessidade de implementação das políticas públicas para crianças e adolescentes consolidadas na legislação vigente (Conselho Nacional dos Direitos da Criança e do Adolescente [CONANDA], 2013).

Não há como deixar de mencionar os argumentos contrários à diminuição da maioridade penal, apresentados pelo presidente da Ordem dos Advogados do Brasil (OAB), Marcus Vinícius Furtado. Ele reafirmou a inconstitucionalidade da proposta e destacou que o Estado deve efetivar as políticas públicas da população infantojuvenil com investimentos em educação, lazer, reinserção dos adolescentes no meio social e no mercado de trabalho, pois essa seria a medida adequada para combater a violência (Ordem dos Advogados do Brasil [OAB], 2013).

O Conselho Federal de Psicologia (CFP) divulgou, em junho de 2013, parecer contrário à aprovação da redução da maioridade penal. Em síntese, destacou-se que a compreensão do adolescente que comete ato infracional não pode se dar em uma perspectiva individual, já que seu desenvolvimento é atravessado pelo contexto relacional, social e histórico. Foi enfatizado, ainda, o caráter pedagógico das medidas socioeducativas, norteando o desenvolvimento humano saudável, em contraposição às práticas repressivas de reclusão. No entanto, o Estado brasileiro tem fracassado em oportunizar esse desenvolvimento às crianças e aos adolescentes por meio da garantia de direitos. Para o CFP, não se soluciona a violência por meio da culpabilização e punição do sujeito que cometeu o ato, e sim pela ação das instâncias sociais, políticas, econômicas e psíquicas que a produzem. Reduzir a maioridade penal, portanto, seria tratar os efeitos, e não a causa da violência (Conselho Federal de Psicologia [CFP], 2013).
Com relação aos estudos sobre adolescentes autores de atos infracionais, considera-se que os atos cometidos por adolescentes representam falhas nas políticas sociais básicas, no lazer, na escola, no Estado e na sociedade. Dessa forma, todos esses setores estão implicados na garantia de direitos, como afirma Castro (2002).

Sousa et al. (2009), em seu estudo "O perfil de adolescentes autores de atos infracionais atendidos pelo sistema socioeducativo de Goiás", concluíram que esses jovens pertencem a famílias de baixa renda, com a presença de pais e filhos no mercado informal, sem vínculos empregatícios e com inserção precoce de crianças no mercado de trabalho. Destacou-se também a incidência de evasão escolar e do uso de drogas entre os adolescentes. O tipo de infração predominante cometida pelos adolescentes atendidos referiu-se às infrações de cunho patrimonial, como roubos e furtos.

Diante disso, foi sublinhada que a verdadeira raiz da violência e da criminalidade encontra-se na desigualdade social, no baixo nível de escolaridade, somado ao baixo poder aquisitivo e dificuldade de acesso ao mercado de trabalho. Vale a pena chamar atenção para a observação de Sousa et al. (2009) a respeito das conclusões do seu estudo, o qual não pretende associar pobreza e criminalidade, considerando-se que as infrações estão presentes nas mais diversas classes sociais, entretanto, os encaminhamentos jurídicos destinados aos infratores são diferenciados.

Esses adolescentes representam uma parcela da população que é chamada de "menor", termo pejorativo, alvo de preconceito e estigma, utilizado por grupos sociais que insistem em encarcerar cada vez mais os adolescentes de periferias urbanas. São adolescentes com baixa escolaridade, em sua maioria, negros e pobres, inseridos em famílias culpabilizadas pelas condições de vida presentes em um país marcado pela desigualdade socioeconômica (Lemos, 2013).

Ao propor a redução da maioridade penal, a sociedade e o Estado se colocam na contramão das suas responsabilidades, não levando em consideração as condições de vida dos adolescentes apresentadas nos estudos, ao mesmo tempo em que, conforme observa Lemos (2013, p. 29), negligenciam o fato de que "cárcere produz mais cárcere e dor, mais vingança e ressentimento. Encarcerar adolescentes e cada vez mais cedo é a reação do fracasso de uma sociedade em proteger e garantir os direitos fundamentais".

\section{Considerações Finais}

Apesar dos posicionamentos contrários à redução da maioridade penal apresentados por diversos setores que atuam no âmbito dos direitos humanos e de pesquisadores que se debruçam sobre essa temática, um grupo de parlamentares respaldados pelas pesquisas de opinião 
pública permanece defendendo e considerando essa medida como forma de solucionar a violência. Tal consideração reduz o fenômeno à esfera individual, encobrindo as determinações históricas, políticas, econômicas e psicossociais da violência. A mídia também contribui para esse entendimento ao espetacularizar o crime, tratando-o a partir de causas pessoais, não proporcionando o diálogo e a discussão sobre as multideterminacões da violência (Teixeira, 2013).

Nesta discussão, é importante considerar que, apesar de o ECA e do SINASE serem criticados e apontados como legislação que confere apenas impunidade ao adolescente que comete ato infracional, eles ainda não foram efetivamente implementados em sua íntegra. A realidade dos estabelecimentos socioeducativos atesta a distância entre o que é previsto em lei e o que é colocado em prática. Além disso, nem mesmo os direitos mais básicos são garantidos aos "menores marginalizados".

O SINASE prevê medidas como a melhoria do acesso e da qualidade das políticas públicas, o que possibilita a prevenção de atos infracionais por adolescente, além de reduzir os casos de reincidência. Em contrapartida, a medida simplista de rebaixar a maioridade penal exclui e segrega ainda mais adolescentes que foram privados de mecanismos de proteção e promoção social ao longo do processo histórico.

Nesse sentido, considera-se que a medida de encarcerar cada vez mais cedo os adolescentes representa um retrocesso aos direitos conquistados e comprova o fracasso do Estado em garanti-los. Significa adotar uma solução falsa para resolver os conflitos sociais com o aprisionamento e de investir menos nas potencialidades destes sujeitos.

Diante disso, faz-se necessário problematizar, interrogar e desnaturalizar a responsabilização individual do adolescente autor de atos infracionais. Esclarecer as múltiplas e complexas determinações da violência e as condições nas quais esses atos são cometidos, além de ousar propor estratégias que permitam ao adolescente superar a sua condição social por meio de políticas públicas que favoreçam a construção da identidade, autonomia, responsabilidade e socialização. É por isso que essa temática merece continuar sendo explorada no âmbito científico pelas mais diversas áreas, a fim de contribuir para disseminação de argumentos esclarecedores, tornando possível criar condições para desenvolver uma visão de justiça social tão ausente no clamor pela redução da maioridade penal.

\section{Referências}

Arantes, E. M. M. (2013). Sobre as propostas de redução da maioridade penal. In Conselho Federal de Psicologia, Redução da maioridade penal: socioeducação não se faz com prisão (pp. 9-13). Brasília: Conselho Federal de Psicologia.

Campos, M. S. (2009). Mídia e Política: a construção da agenda nas propostas de redução da maioridade penal na Câmara dos Deputados. Opinião Pública, 15(2), 478-509.

Campos, R., \& Francischini, H. R. (2005). Adolescente em conflito com a lei e medidas socioeducativas: Limites e (im)possibilidades. PSICO, 36 (3), 267-273.

Castro, A. L. S. (2002). Os adolescentes em conflito com a lei. In Conselho Federal de Psicologia, Adolescência e psicologia: concepções, práticas e reflexões críticas (122-129). Rio de Janeiro: Conselho Federal de Psicologia.

Conselho Federal de Psicologia. (2010). Referências técnicas para atuação de Psicólogos no âmbito das medidas socioeducativas em unidades de internação. Brasília: Conselho Federal Psicologia.

Conselho Nacional dos Direitos da Criança e do Adolescente. (2006). Sistema Nacional de Atendimento Socioeducativo (Sinase). Brasília: CONANDA.

Conselho Nacional dos Direitos da Criança e do Adolescente. (2013). Nota pública sobre a redução da maioridade penal. Recuperado de: http://www.crianca.mppr.mp.br/ modules $/$ conteudo/conteudo.php?conteudo=1414.

Conselho Nacional do Ministério Público. (2013). Um olhar atento às Unidades de internação e semiliberdade para adolescentes. Relatório da Resolução n 67/2011. Brasília: Conselho Nacional do Ministério Público.

Datafolha. (2013). Maioridade Penal. Recuperado de: http://datafolha.folha.uol.com.br/ opiniaopublica/2013/04/1264396-93-defendemreducao-da-maioridade-penal.shtml.

Debord, G. (1997). A sociedade do espetáculo: comentários sobre a sociedade do espetáculo. Rio de Janeiro: Contraponto.

Estatuto da criança e do adolescente (ECA). (1990). Lei. 8.069, de 13 de julho de 1990. Brasília: Conanda.

Fundo das Nações Unidas para a Infância. (2007). Nota pública do UNICEF sobre a morte de João Hélio. Pelo direito a crescer sem violência. Recuperado de: http://www.crianca.mppr.mp.br/modules/conteudo/ conteudo.php? conteudo $=325$. 
Gomide, P. I. C. (2009). Menor infrator: a caminho de um novo tempo ( $2^{\mathrm{a}}$ ed.). Curitiba: Juruá.

Hage, S. M., \& Araújo, M. de N. (2013). Pela consolidação dos marcos legais que asseguram direitos à criança e ao adolescente. In Conselho Federal De Psicologia, Redução da maioridade penal: Socioeducação não se faz com prisão (pp. 31-34). Brasília: Conselho Federal de Psicologia.

Lemos, F. C. S. (2013). Uma crítica à volúpia punitiva da sociedade frente aos adolescentes. In Conselho Federal de Psicologia, Redução da maioridade penal: Socioeducação não se faz com prisão (pp. 19-21). Brasília: Conselho Federal de Psicologia.

Márques, F. T. (2011). Intolerâncias e in(ter)venções: "Menores" e "crianças" no imaginário social brasileiro. Revista Latinoamericana de Ciencias Sociales, Ninez y Juventud, 9, $797-809$.

Ordem dos Advogados do Brasil. (2013). OAB no Senado: Reduzir a maioridade penal não trará redução contra crimes. Recuperado de: http://www.oab.org.br/ noticia/25701/oab-no-senado-reduzir-a-idade-penalnao-trara-protecao-contra-crimes .

Rizzini, I. (2008). O século perdido: raízes históricas das políticas públicas para a infância no Brasil ( $2^{\mathrm{a}}$ ed.). São Paulo: Cortez.

Secretaria de Direitos Humanos da Presidência da República. (2012). Atendimento Socioeducativo ao adolescente em conflito com a lei: Levantamento Nacional 2011. Recuperado de: http://www.sdh.gov.br/assuntos/ criancas-e-adolescentes/pdf/SinaseLevantamento2011. pdf/view.

Senado Federal. (2012). Proposta de Emenda Constituição n. 33 de 2012. Recuperado de http://www25.senado. leg.br/web/atividade/materias/-/materia/106330

Sistema Nacional de Atendimento Socioeducativo (SINASE). (2012). Lei. 12.594, de 18 de janeiro de 2012. Brasília: Conanda.

Sousa, S. M. G. et al. (2013). O perfil dos adolescentes privados de liberdade em Goiás. In S. M. G. Sousa (Org.), Adolescentes autores de atos infracionais: Estudos psicossociais (pp. 15-34). Goiânia: Editora PUC Goiás.

Teixeira, M. L. T. (2013). Redução da maioridade penal... mais uma vez!. In Conselho Federal de Psicologia,
Redução da maioridade penal: socioeducação não se faz com prisão (pp. 19-21). Brasília: Conselho Federal de Psicologia.

Volpi, M. (Org.). (1997). O adolescente e o ato infracional. São Paulo: Cortez Editora.

Zappe, J. G., Ferrão, I. S., Santos, C. R., Silveira, K. S. S., Costa, L. P., \& Siqueira, T. V. (2011). A internação de adolescentes em conflito com a lei: uma reflexão teórica sobre o sistema socioeducativo brasileiro. Adolescência e Conflitualidade, 5, 112-133.

\section{Endereço para correspondência:}

Mariana Fonseca Cavalcanti

Endereço: Rua Praia de Pititinga, n 9083 , Ponta Negra. Natal/RN, CEP 59092-350.

E-mail: marianafonsecacavalcanti@gmail.com

\section{Endereço para correspondência:}

Isabel Fernandes de Oliveira

Endereço: Rua Lúcia Viveiro, 1155, Bloco A/301, Neópolis. Natal/RN, CEP 590086-005.

E-mail: fernandes.isa@gmail.com 